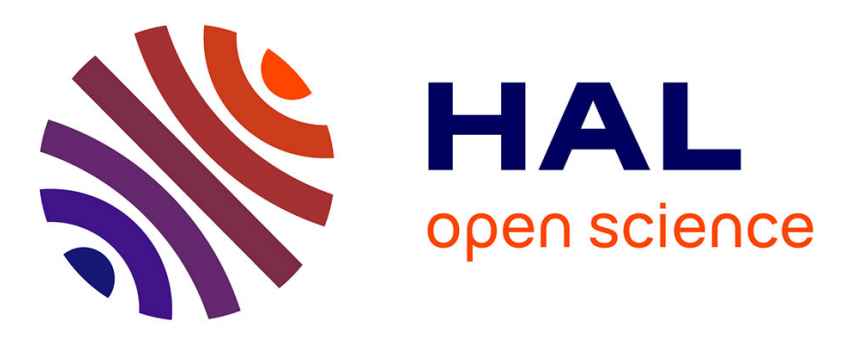

\title{
Linear correlation between specific surface and grafting density of tunable aerogels of microfibrillated cellulose from different origins
}

Emilie Ressouche, Sonia Molina-Boisseau, Karim Mazeau, David Guérin, Matthieu Schelcher, Laurent Heux

\section{To cite this version:}

Emilie Ressouche, Sonia Molina-Boisseau, Karim Mazeau, David Guérin, Matthieu Schelcher, et al.. Linear correlation between specific surface and grafting density of tunable aerogels of microfibrillated cellulose from different origins. Cellulose, 2020, 27 (14), pp.7979-7995. 10.1007/s10570-020-03319-y . hal-03453808

\section{HAL Id: hal-03453808 \\ https://hal.science/hal-03453808}

Submitted on 28 Nov 2021

HAL is a multi-disciplinary open access archive for the deposit and dissemination of scientific research documents, whether they are published or not. The documents may come from teaching and research institutions in France or abroad, or from public or private research centers.
L'archive ouverte pluridisciplinaire HAL, est destinée au dépôt et à la diffusion de documents scientifiques de niveau recherche, publiés ou non, émanant des établissements d'enseignement et de recherche français ou étrangers, des laboratoires publics ou privés. 


\section{Query Details}

Back to Main Page

1. Please confirm the section headings are correctly identified.

2. Kindly check and confirm inserted Fig. 10 citation is correct in main text.

\section{Original Research}

\section{Linear correlation between specific surface and grafting density of tunable aerogels of microfibrillated cellulose from different origins}

Emilie Ressouche, 1,2

Sonia Molina-Boisseau,

Karim Mazeau, 1

David Guérin, 3

Matthieu Schelcher, 3

Laurent Heux, $1 \square$

Email laurent.heux@cermav.cnrs.fr

1 CNRS, CERMAV, Univ. Grenoble Alpes, 38000 Grenoble, France

2 Department of Applied Physics, Aalto University, P.O. Box 15100, 02150 Espoo, Finland

3 Centre Technique du Papier, 38044 Grenoble, France 
Received: 22 January 2020 / Accepted: 25 June 2020

\section{Abstract}

Cellulose aerogels with variable specific surface areas were prepared by freeze-drying cellulose microfibrillar suspensions dispersed in mixtures of water and tert-butyl alcohol (TBA). Varying the composition of solvent used for the suspensions and the origin and composition of the microfibrils allowed to extensively tune the specific surface area of these aerogels, with values ranging from 32 to $280 \mathrm{~m}^{2} / \mathrm{g}$. Depending on the solvent mixture composition, these aerogels presented substantial morphological differences, attributed to the templating power of the various crystals obtained during the freezing of the solvent mixtures. The aerogels were hydrophobized with sebacoyl chloride in a gas-phase reaction operated under conditions of either full or partial derivatization of the accessible surface. For fully grafted specimens, a linear correlation could be established between the overall degree of substitution of the grafted samples and the specific surface area of the aerogels before grafting. From the slope of this correlation line, an average number of grafted molecules per surface area of approximately 3 molecules $/ \mathrm{nm}^{2}$ could be calculated. Atomic-scale models gave a plausible overview of the full surface coverage of the aerogel microfibrils in good agreement with the experimental data. Contact angle measurements confirmed the hydrophobicity of the grafted aerogels, as well as the presence of heterogeneities for the partially grafted samples.

\section{Keywords}

Cellulose microfibrils

Aerogels

Surface modification

Gas-phase

CP-MAS NMR

Hydrophobization

Electronic supplementary material 
The online version of this article (https://doi.org/10.1007/s10570-020-03319-y) contains supplementary material, which is available to authorized users.

\section{Introduction}

In a seminal half a page paper, Kistler (1931) initially described how the inner structure of gels could be preserved by critical point drying, leading according to him to a "coherent aerogel of unchanged volume". First developed for silica, it was soon found that the technique could be extended to a host of inorganic and organic gels and at present there seems to be no limit to the number of aerogels that can be produced with such a technique. In common, all the aerogels share very unique properties ranging from low density, very large specific surface areas, low thermal conductivity, together with excellent shock absorption and acoustic characteristics (Gesser and Goswami 1989; Hüsing and Schubert 1998; Pierre and Pajonk 2002).

Even if cryogels, which result from the freeze-drying of gels, present somewhat lower specific surface areas than those produced by critical point drying (Gun'ko et al.2013), they are extensively studied since they are simpler and cheaper to produce and in the best cases, their properties approach those of the critical-point dried aerogels. At present the term "aerogel" encompasses both the aerogels produced by critical point drying and the cryogels (Pierre and Pajonk 2002; Vareda et al. 2018). In the latter, the specific surface is created by the solvent crystals: during the freezing step, they expel the core of the gelled structure and thus lead to a distribution of pore sizes that matches those of the solvent crystallites. These aerogels can be considered as materials templated by the solvent crystals (Gutierrez et al. 2008). Besides aqueous gels where water crystallization can create substantial damage to the gel during ice crystal growth, some organic solvents and their drying by sublimation are less damaging to the gels when they have been solvent exchanged from aqueous environment (Ziegler et al. 2017; Ren et al. 2014; Pons et al. 2012). In this line, acetonitrile (Ren et al. 2014) and cyclohexane (Schaefer et al. 2013), are quoted as good candidates, but it is $t$-butyl alcohol (TBA) either pure or in mixture with water, which is the most frequently used ( Kasraian and DeLuca 1995a, b ; Tamon et al. 1999; Tamon et al. 2000; Borisova et al. 2015). Depending on the composition, the phase diagram of TBA/water system presents two eutectic points, at around 20 and 90 wt\% TBA/water (Ott et al. 1979; Kasarian and DeLuca 1995a). For aerogels of 
several polysaccharides, a freeze-drying at the eutectic concentrations of TBA/water was clearly associated with the observation of maximal mesoporosity (Borisova et al. 2015).

With the incentive of developing green biodegradable materials, aerogels based on bio-sourced polymers and in particular on polysaccharides such as cellulose, pectin, starch, chitin, etc. have been prepared (Garcia-Gonzales et al. 2011; Ding et al. 2012; Rudaz et al. 2014; Druel et al. 2017; Groult and Budtova 2018). In this context, aerogels of nanocellulose have triggered the greatest interest. Nanocelluloses occur in two forms, namely cellulose nanocrystals (CNCs) or microfibrillated cellulose (MFCs) (Klemm et al. 2005; Moon et al. 2011, Isogai 2013). Aerogels made from MFCs present enhanced flexibility as opposed to those made from CNCs (de France et al. 2017). Indeed, the skeleton of the MFCs aerogels consists of entangled semi-crystalline microfibrils of rather low density $\left(1.6 \mathrm{~g} / \mathrm{cm}^{3}\right)$ (Nishiyama et al. 2002), high strength (2-6 GPa) (Saito et al. 2013) and high elastic modulus (115-150 GPa) (Iwamoto et al. 2009; Nishiyama 2009). MFCs aerogels do not show the detrimental brittleness frequently encountered with inorganic aerogels, but display a high compression strength, a high flexibility and perfect recovery after large deformation, being at the same time tough and flexible (Sehaqui et al. 2010, 2011; Liebner et al. 2010; Chen et al. 2011; Pääkkö et al. 2008). In addition, they show only a limited retraction during the freeze-drying step (Chen et al. 2014).

Nanocellulose aerogels present a hydrophilic character, related to the numerous hydroxyl groups located at the surface of the aerogel skeleton. These groups impart a water-uptake property that can be advantageous for some applications, such as the cleaning of aqueous effluents (Chen et al. 2011, 2014). The hydrophilicity of nanocellulose aerogels is detrimental for other end-uses and several protocols for the hydrophobization of the nanocellulose aerogels have been devised. For this, surface silanization (Aulin et al. 2010; Lazzari et al. 2017; Zhou et al. 2016; Wang et al. 2015) has been implemented and the resulting hydrophobized aerogels have proven excellent for oil spillage cleanup. In our laboratory, a gas-phase hydrophobization of nanocellulose aerogels was developed by exposing them to vapors of long chain alkyl chloride reagents under low vacuum and high temperature (Berlioz et al. 2009; Fumagalli et al. 2015). These alkyl chlorides react with the hydroxyl moieties of cellulose, thus leading to the hydrophobization of the nanocellulose aerogels. Remarkably, if a 
diacyl chloride such as sebacoyl chloride was used, the esterification was restricted exclusively to the surface of the aerogel skeleton, without attacking the core of the constituting microfibrils (Fumagalli et al. 2015).

In previous studies, $\mathrm{CNCs}$ and MFCs aerogels were prepared from TBA suspensions, We found that the use the solvent exchange from water to TBA suspension further lyophilized exhibited a huge specific surface area of $100 \mathrm{~m}^{2} / \mathrm{g}$ and $160 \mathrm{~m}^{2} / \mathrm{g}$ for MFCs and CNCs aerogels respectively, that could be massively functionalized by gas phase esterification (Fumagalli et al. 2013a, b). As aforementioned, the use of difunctional reagents appeared interestingly to restrict the modification to the surface, for example when esterified with sebacoyl chloride and most likely proportionally to the specific surface (Fumagalli et al. 2015). This last observation is of high importance, as functionalized cellulose nanoparticles with disulfur reactive moieties located only at the surface can be prepared and exhibit outstanding reinforcing properties in elastomer, comparable to their silica counterparts (Fumagalli et al. 2018). In order to further investigate the relationships between specific surface and grafting density, we prepared aerogels with different mixture ratios in order to modulate the specific surface area. We also extended the aerogels preparation and hydrophobization process to microfibrils obtained from pulps of different origins in order to have information on the influence of the cellulosic surface. We have evaluated first the incidence of adding water to TBA to follow the variations of the specific surface area and morphology of the resulting MFCs aerogels. Then, MFCs from three types of cellulose pulps containing different amounts of hemicellulose and residual lignin were also investigated and when converted into aerogels, their morphology and specific surface area were compared. Their use for subsequent gas-phase esterification was also undertaken and the characteristics of the resulting surfaceesterified products were analyzed in terms of grafting density and surface properties.

\section{Experimental}

\section{Materials}

Microfibrillated cellulose (MFC) suspensions were produced at Centre Technique du Papier (CTP), Grenoble, France, from three different pulps: (1) a bleached softwood sulfite dissolving pine pulp from Domsjö (Sweden), (2) a never dried bleached birch kraft pulp from Stora Enso (Sweden), and (3) an unbleached birch 
kraft pulp from Stora Enso (Sweden). MFC from the two bleached pulps were processed using a method developed by Lindström et al. (2007) and Pääkkö et al. (2007) based on a mechano-enzymatic pre-treatment, optimized at CTP and followed by homogenization at high pressure. The pulps were first refined at 3.5 wt $\%$ aqueous suspension to a 25 Schopper-Riegler degree ( $\left.{ }^{\circ} \mathrm{SR}\right)$, enzymatically treated with endoglucanase FiberCare R (Novozymes) at $0.1 \mathrm{~kg} / \mathrm{t}$ during $1 \mathrm{~h}$ at 50 ${ }^{\circ} \mathrm{C}$ and $\mathrm{pH} 5$, post-refined to $80{ }^{\circ} \mathrm{SR}$, diluted to $2 \mathrm{wt} \%$, and mechanically treated by high-pressure homogenization with a GEA Niro Soavi NS2006 homogenizer. The homogenization consisted in a first pass at 500 bar, a second pass at 1000 bar, and 4 subsequent passes at 1500 bar. The MFCs from unbleached birch pulp were produced according to a new process developed by Meyer et al. (2017). After dispersing the fibers in water, the suspensions were directly treated with a commercial cellulase $\left(1 \mathrm{~h}, 50^{\circ} \mathrm{C}, 20 \mathrm{ECU} / \mathrm{g}\right)$ and then extensively refined under specific conditions to reduce the mean area-weighted fiber length to a value below $200 \mu \mathrm{m}$. This suspension was finally homogenized by 3 passes at 1500 bar with a GEA Niro Soavi NS2075 homogenizer.

Sebacoyl chloride (111-19-3, 92\%) and TBA (75-65-0, 99.5\%), were acquired from Sigma Aldrich and used without further purification. Acetone (67-64-1, 99.9\%) was purchased from Biosolve and was used without purification.

\section{Composition of the pulps}

The composition of the different pulps was determined following classical sugar analysis (Falcoz-Vigne et al. 2017).

\section{Table 1}

Composition of the pulps used for the production of the MFC suspensions

\begin{tabular}{|l|l|l|l|l|}
\hline Pulp MFCs & $\begin{array}{l}\text { Cellulose } \\
(\mathbf{\%})\end{array}$ & $\begin{array}{l}\text { Xylan } \\
(\mathbf{\%})\end{array}$ & $\begin{array}{l}\text { Glucomannan } \\
\mathbf{( \% )}\end{array}$ & $\begin{array}{l}\text { Lignin } \\
\mathbf{( \% )}\end{array}$ \\
\hline Bleached pine sulfite & 96.5 & 1.5 & 2 & - \\
\hline \begin{tabular}{l} 
Bleached birch kraft \\
\hline $\begin{array}{l}\text { Unbleached birch } \\
\text { kraft }\end{array}$
\end{tabular} & 74.0 & 25.7 & 0.3 & - \\
\hline
\end{tabular}




\section{Preparation of the aerogels}

Solvent exchange

Solvent exchanges were achieved by applying three centrifugation/re-dispersion cycles to dispersions of never-dried MFC in water. The MFC suspensions were centrifuged at $11,200 \mathrm{rpm}$ for $1.5 \mathrm{~h}$, at $20^{\circ} \mathrm{C}$ and the supernatant removed. The selected TBA/water mixture was then added to the MFC sediments, which were re-dispersed with an Ultra Turrax homogenizer operated at 10,000 rpm for 5 min. Amount of the same selected TBA/water mixture was then added to get the required concentrations of MFC, which was systematically set at $1.25 \mathrm{wt} \%$, unless otherwise specified.

AQ1

\section{Freezing and freeze-drying}

For fast freezing, the MFC suspensions were poured into a Teflon ${ }^{\circledR}$ mold positioned on a copper block partially immersed in liquid nitrogen. The cooling, inducing a freezing of the suspension, was maintained for approximately $1 \mathrm{~h}$. The Teflon ${ }^{\circledR}$ mold containing the frozen suspension was then freeze-dried for 3 days.

\section{Specific surface area characterization by BET method}

The samples (at least $80 \mathrm{mg}$ for a $100 \mathrm{~m}^{2} / \mathrm{g}$ aerogel) were introduced into a $9 \mathrm{~mm}$ cell and dried overnight at $105^{\circ} \mathrm{C}$ under vacuum. After drying, the amount of cellulose was weighed and the container was filled with helium before performing the measurement. Nitrogen adsorption was measured with a surface area analyzer Nova 1200e (Quantachrome Instruments). Specific surface area was estimated by BET method (Brunauer et al. 1938) from adsorption-desorption isotherms at $77 \mathrm{~K}$ in the pressure range of $0.01-0.3$ bar. At least two measurements were made for each sample in order to verify the reproducibility, and the values were averaged. A systematic 5\% error scale was applied to the resulting values.

\section{Scanning electron microscopy (SEM) imaging}

Cellulose aerogel fragments were cut with a razor blade. Cross sections were coated with $\mathrm{Au} / \mathrm{Pd}$ and observed with a scanning electron microscope (SEM) QUANTA FEG 250 (FEI) operated under secondary electron mode, and low or high vacuum depending on the charging effects. 


\section{Grafting process}

The grafting process was adapted from previous protocols devised in our laboratory (Berlioz et al. 2009; Fumagalli et al. 2013a). The samples were introduced into polyamide hessian bags (pore sizes of $100 \mu \mathrm{m}$ ) and dried at 60 ${ }^{\circ} \mathrm{C}$ for $3 \mathrm{~h}$ to remove any residual water. Ten equivalents of sebacoyl chloride, i.e. the number of equivalents of reagent introduced with respect to the total number of anhydroglucose units (AGU), in a Petri dish was positioned at the bottom of a thermostated double walled reactor. A Teflon ${ }^{\circledR}$ grid was installed above the Petri dish, so that the cellulose aerogels were not in contact with the alkyl chloride. Hessian bags with pore size $100 \mu \mathrm{m}$ containing dried cellulose aerogel were placed onto the Teflon ${ }^{\circledR}$ grid and the reactor was closed and set under vacuum at $100{ }^{\circ} \mathrm{C}$ for given times. For complete grafting, the process was applied during $12 \mathrm{~h}$, at $0.5 \mathrm{mbar}$, under nitrogen atmosphere. For partial grafting, it was applied during $3 \mathrm{~h}$, at $250 \mathrm{mbar}$, under nitrogen atmosphere. After grafting, the samples were washed in a Soxhlet extractor with $400 \mathrm{~mL}$ acetone for $6 \mathrm{~h}$. After oven-drying at $60^{\circ} \mathrm{C}$ for $12 \mathrm{~h}$, the samples were characterized by ${ }^{13} \mathrm{C}$ solid-state NMR.

\section{Solid-state ${ }^{13} \mathrm{C}$ NMR spectroscopy analysis}

Solid-state NMR experiments were performed with a Bruker Avance DSX 400 $\mathrm{MHz}$ spectrometer operating at $100.6 \mathrm{MHz}$ for ${ }^{13} \mathrm{C}$, using the combination of cross-polarization, high-power proton decoupling and magic angle spinning (CP/MAS) method. The spinning speed was set at $12,000 \mathrm{~Hz}$. The ${ }^{1} \mathrm{H}$ radio frequency field strength was set to give a $90^{\circ}$ pulse duration of $2.5 \mu \mathrm{s}$. The ${ }^{13} \mathrm{C}$ radio frequency field strength was obtained by matching the Hartman-Hahn conditions at $60 \mathrm{kHz}$. Recording at least 2000 scans with contact time and recycle delay, respectively, of $2 \mathrm{~ms}$ and $2 \mathrm{~s}$ represented standard conditions. The acquisition time was set at $35 \mathrm{~ms}$ and the sweep width at 29,400 $\mathrm{Hz}$.

The degree of substitution (DS) of the cellulose esters was analyzed using ssNMR spectroscopy by comparing the cellulose esters carbonyl carbon (173 ppm) and cellulose esters alkyl carbon (30 ppm) integrals with the cellulose C1 signal (104 ppm) integral. Three integrations were realized, and the values were averaged. DS was calculated by dividing the carbonyl integration by two, and the alkyl integration by eight, to take into account the functionality of the sebacoyl chloride as well as the number of carbon atoms involved in the signals. 


\section{Fourier transform infrared (FTIR) spectroscopy analysis}

Fourier Transform Infrared spectroscopy was performed with a PerkinElmer Spectrum Two apparatus, with an ATR UATR interface, equipped with the Spectrum acquisition software. The samples were deposited on the ATR interface without further preparation.

\section{Results and discussion}

\section{MFC aerogels with tunable specific surface area}

Aerogels resulting from freeze-drying under different TBA/water compositions

In this part of the study, a series of MFCs aerogels was prepared by fast freezing $1.25 \%(\mathrm{w} / \mathrm{w})$ suspensions of MFCs from bleached pine sulfite pulp in (1) water, (2) pure TBA, and (3) various mixtures of water and TBA. As a general rule, a fast freezing induces extensive nucleation and growth of solvent crystallites of small size, which thus will lead to small pores during the subsequent freezedrying process in the aerogel preparation. In addition, for solvent mixtures at the eutectic composition, we expect to obtain still smaller solvent crystallites and thus smaller pores and aerogels with still increased specific surface area. The literature reports two eutectic compositions in the water/TBA phase diagram, at 20 and 90\% TBA (weight fraction) (Ott et al. 1979, Kasraian and DeLuca 1995a, b Borisova et al. 2015).

A plot of specific surface area of the MFCs aerogels, achieved by nitrogen adsorption and BET method, in terms of TBA composition (Fig. 1) indicates a relationship between the sample specific surface and the features of the TBA/water melting diagram. Clearly, the first specific surface maximum of 60 $\mathrm{m}^{2} / \mathrm{g}$ at $25 \mathrm{wt} \% \mathrm{TBA} /$ water can be associated with the first eutectic point. A minimum is also observed around $55 \mathrm{wt} \% \mathrm{TBA} /$ water, as in the case of freezedried pectin (Borisova et al. 2015), but unlike in the case of pectin, a maximum of $90 \mathrm{~m}^{2} / \mathrm{g}$ in specific surface was obtained with pure TBA. It is not clear whether this second maximum can be related to the second eutectic point, which occurs at a composition very close to pure TBA.

\section{Fig. 1}

Evolution of measured specific surface area of bleached pine sulfite MFC aerogels, 


\section{in TBA/water mixtures at different proportions}

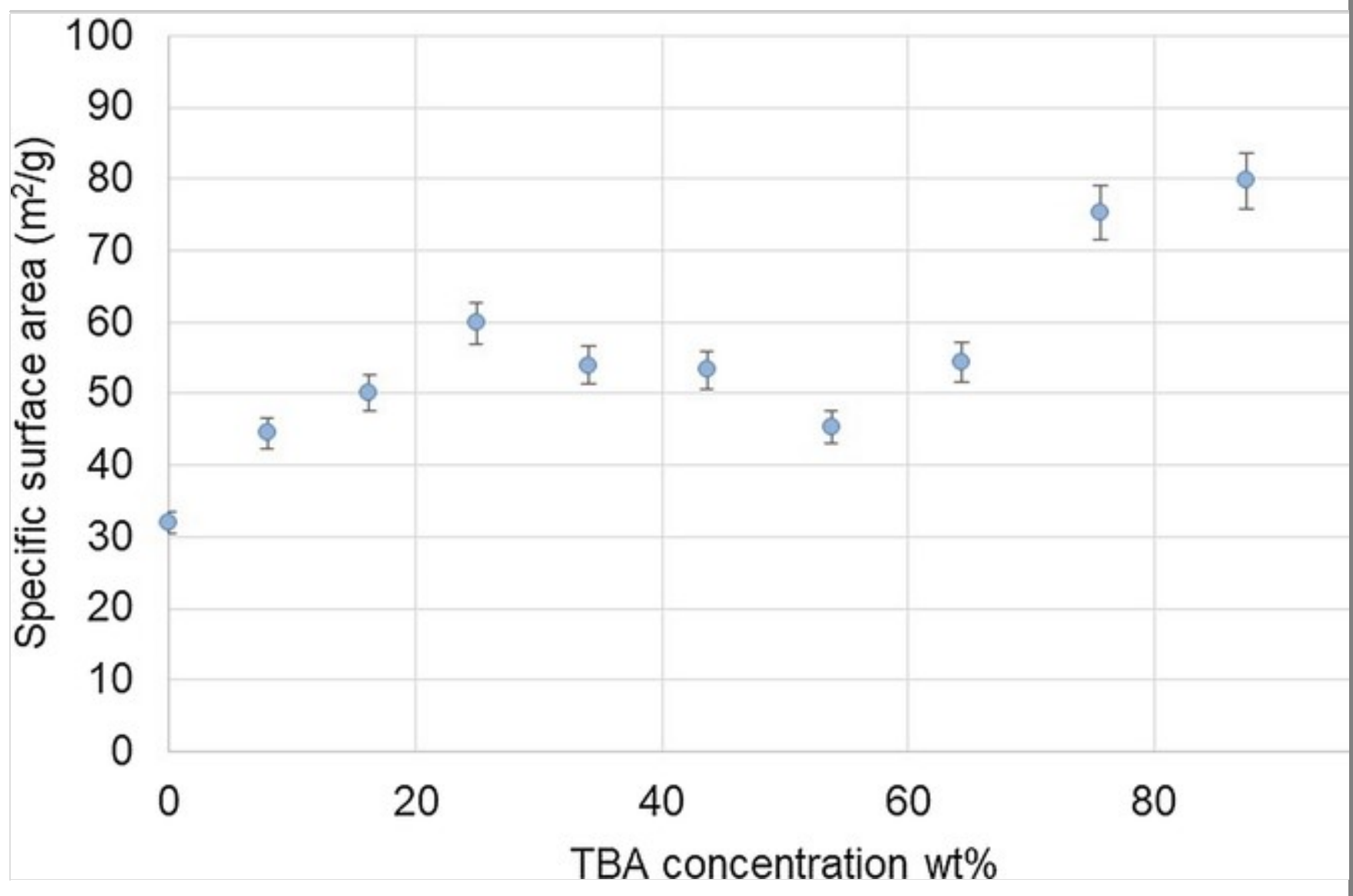

To follow the evolution of their morphology, the aerogels were sectioned and observed by SEM. Significant images are presented in Fig. 2, with aerogels prepared from compositions ranging from pure water to pure TBA. Figure $2 \mathrm{a}$ corresponds to a sample frozen from pure water. In this sample, the formation of fairly large ice crystals and their subsequent freeze-drying have left large holes in the structure, pushing the microfibrils into large compact sheets, consolidated at the ice crystal surfaces and remaining there during the freeze-drying step, as already observed in the so-called freeze-casting process, with size of pores controlled by the freezing rate (Zhang et al. 2005). In Fig. 2b, taken from freezedried microfibrils from a mixture of $25 \mathrm{wt} \% \mathrm{TBA} /$ water, the situation is somewhat different as the cellulose sheets have almost totally vanished, leading to a fluffier morphology, less compact than in Fig. 2a, and devoid of large holes. The disappearance of the cellulose sheets is also correlated with the observation of a much more fibrillar structure, reminiscent of the initial morphology of the microfibrillated cellulose. Likely, this texture results from the first eutectic composition between TBA and water, which occurs close to this concentration. 
Figure $2 \mathrm{c}$ is quite interesting as it shows both a macro- and a micro-porosity. This dual porosity character can be well explained by looking at the phase diagram of TBA/water (Ott et al. 1979, Kasraian and DeLuca 1995a, b; Borisova et al. 2015). At this composition, namely $44 \mathrm{wt} \% \mathrm{TBA} /$ water the frozen mixture contains a mixture of large TBA hydrate crystal, responsible for the large holes, and an eutectic phase likely linked to the origin of the microporosity. In Fig. 2d resulting from the freeze-drying of the sample in pure TBA, the solvents crystals were most probably much smaller than those of pure water, since the cellulose microfibrils are still organized in sheets but far smaller in size than those in Fig. $2 \mathrm{a}, \mathrm{c}$. It is worth to note that besides the presence of a somehow layered organization in the last two samples, sub-micron fibrillated structures are still visible, but the resolution of SEM did not allow to investigate further the ultrastructural organization of these sheets. Interestingly, the sample with the highest specific surface area (from pure TBA) is not the one that exhibits the most spectacularly fibrillar structure, indicating that the apparent porosity (as observed by SEM) and the specific surface area (as measured from nitrogen adsorption isotherms) are not totally correlated, even if the structures with the more compact aspect (freeze-dried from pure water) are obviously the ones with the lowest specific surface area.

\section{Fig. 2}

SEM imaging of MFC aerogels from bleached pine sulfite microfibrils freeze dried from a pure 100 water, b $25 \mathrm{wt} \% \mathrm{TBA} /$ water, c $44 \mathrm{wt} \% \mathrm{TBA} /$ water, d pure TBA. The micron marker corresponds to $5 \mu \mathrm{m}$ 

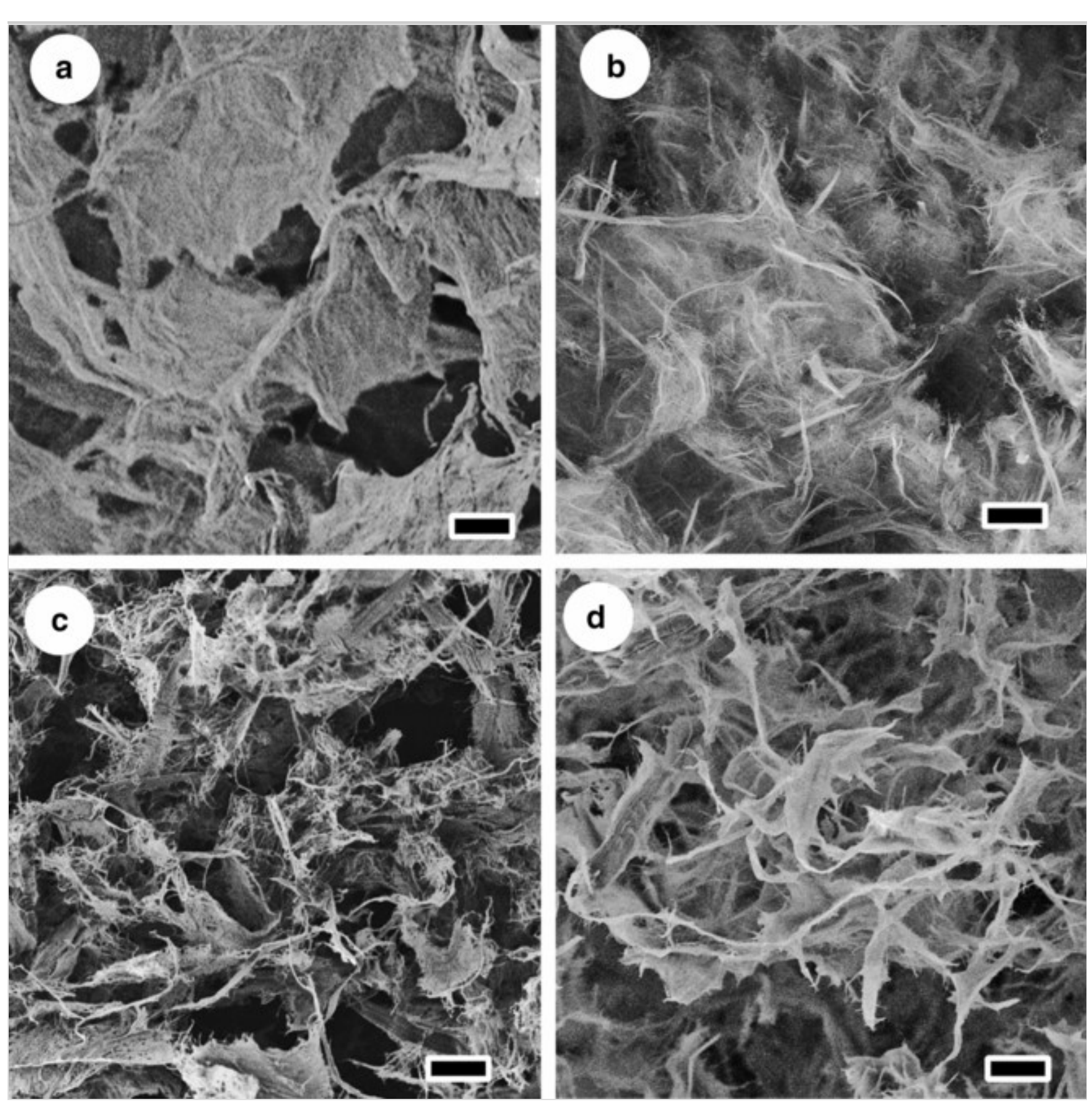

Taken together, these results and observations indicate that cellulose aerogels of tunable specific surface area can be obtained by freeze-drying dispersed cellulose microfibrils suspended in mixtures of various TBA/water compositions. With microfibrils from bleached sulfite pine pulp, aerogels of specific surface areas from 10 to $88 \mathrm{~m}^{2} / \mathrm{g}$ were obtained, the highest value being obtained from samples in pure TBA. These values are somewhat lower than the extreme values for cellulose aerogels, as values as high as $160 \mathrm{~m}^{2} / \mathrm{g}$ (Wang et al. 2017) or even 250 $\mathrm{m}^{2} / \mathrm{g}$ (Sehaqui et al. 2011) have been reported. A reason for our lower values may reside in the state of dispersion of the initial microfibrils, which on its turn 
may depend on the origin of the pulp and of the protocol that was used to pulp and bleach the original wood chips.

As indicated in Table 1, the bleached sulfite pine pulp used here was rather low in residual hemicellulose and devoid of lignin. As we will see in the next section the role of these encrusting components have a significant effect on the specific surface of the aerogels.

\section{Aerogels resulting from cellulose samples of various origins and with different residual chemical compositions}

In this section, aerogels resulting from MFC suspensions in pure water, $45 \mathrm{wt} \%$ TBA/water and pure TBA were prepared from various MFC pulp sources. In addition to MFCs from bleached pine sulfite pulp, MFCs from bleached and unbleached birch kraft pulp were also used. For these samples, the composition in cellulose, hemicellulose and lignin is aforementioned in the Experimental part (Table 1). In Fig. 3, we present the specific surface area for each aerogel. The resulting values demonstrate a tendency similar to what was observed for the pine sulfite bleached MFC aerogels, namely that the specific surface areas were the highest when the suspensions were prepared in pure TBA, intermediate in TBA/water mixtures and quite low in pure water. Such a tendency was observed independently from the origin of the MFC.

\section{Fig. 3}

Specific surface area of MFC aerogels made from the pulp of bleached pine sulfite, bleached birch kraft, unbleached birch kraft, freeze-dried from suspensions in water (dark green), in $45 \mathrm{wt} \% \mathrm{TBA} /$ water (light green), in pure TBA (blue) 


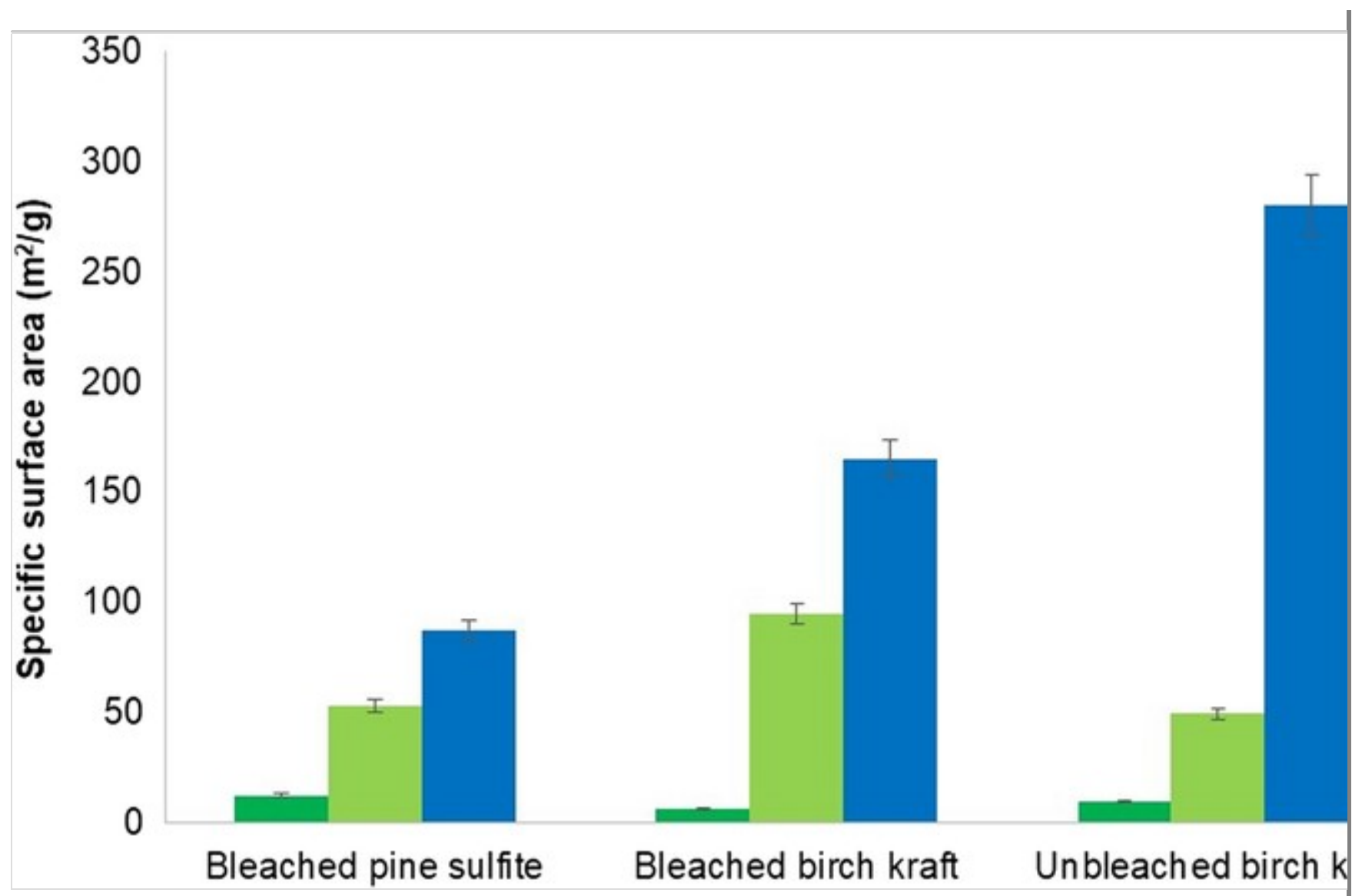

Interestingly, the aerogels obtained from microfibrillated birch kraft pulps presented specific surface areas higher than those from the bleached sulfite pine pulp counterpart. With the samples prepared from pure TBA, there is a doubling of the specific surface area value when going from the bleached pine pulp sample holding minor amount of hemicellulose to the bleached kraft sample where about one fourth of the weight consists of xylan. This drastic increase in surface measurement is likely due to the protecting role of the xylan, mostly located at the microfibrils surface (Arola et al. 2013). The presence of these hemicellulose chains is more prone to protect the MFC from aggregation, especially during the crystallization of TBA, thus leading to a higher specific surface area. In Fig. 3, one also notices a spectacular increase of the surface area between bleached and unbleached samples prepared in pure TBA, with values jumping from 170 to 280 $\mathrm{m}^{2} / \mathrm{g}$. This is remarkable since the only difference between the two samples is a small amount of lignin, which is close to zero in the bleached specimen and only of $2.7 \%$ in the unbleached sample (Table 1 ). When produced from pure water or mixture of water and TBA, the aerogel sample from unbleached birch kraft pulp showed specific surface area values somewhat similar to those of the bleached sulfite pine pulp counterpart. However, in pure TBA environment the value 
jumped from 80 to $280 \mathrm{~m}^{2} / \mathrm{g}$, i.e. an increase by a factor of more than three. This striking difference must be related not only to the presence of surface xylan, but also to the polarity of the MFC surface, which can go from hydrophilic when the pulp samples are fully bleached to partially hydrophobic when residual lignin is present at the microfibril surfaces. This partial hydrophobicity likely allows the lignified microfibrils to be less aggregated in the low polarity TBA (Reichardt and Welton 2010) and thus to end up into a much more open structure after freeze-drying.

When observed by SEM, the sections of the three samples resulting from freezedrying in TBA did not show striking differences (Fig. 4). In each sample, relatively small convoluted sheets of microfibrils were observed, but the large difference in specific surface between sample $4 \mathrm{a}$ and $4 \mathrm{c}$ could not be visualized, indicating again that the pore sizes were obviously too small to be revealed by SEM and the morphology at the macroscale mostly related to the crystallization of the solvent during the freezing step leading to the aerogels.

\section{Fig. 4}

SEM imaging of aerogels freeze-dried in pure TBA from MFC suspensions of a bleached sulfite pine pulp, b bleached birch kraft pulp, $\mathbf{c}$ unbleached birch kraft pulp. The micron marker corresponds to $5 \mu \mathrm{m}$ 

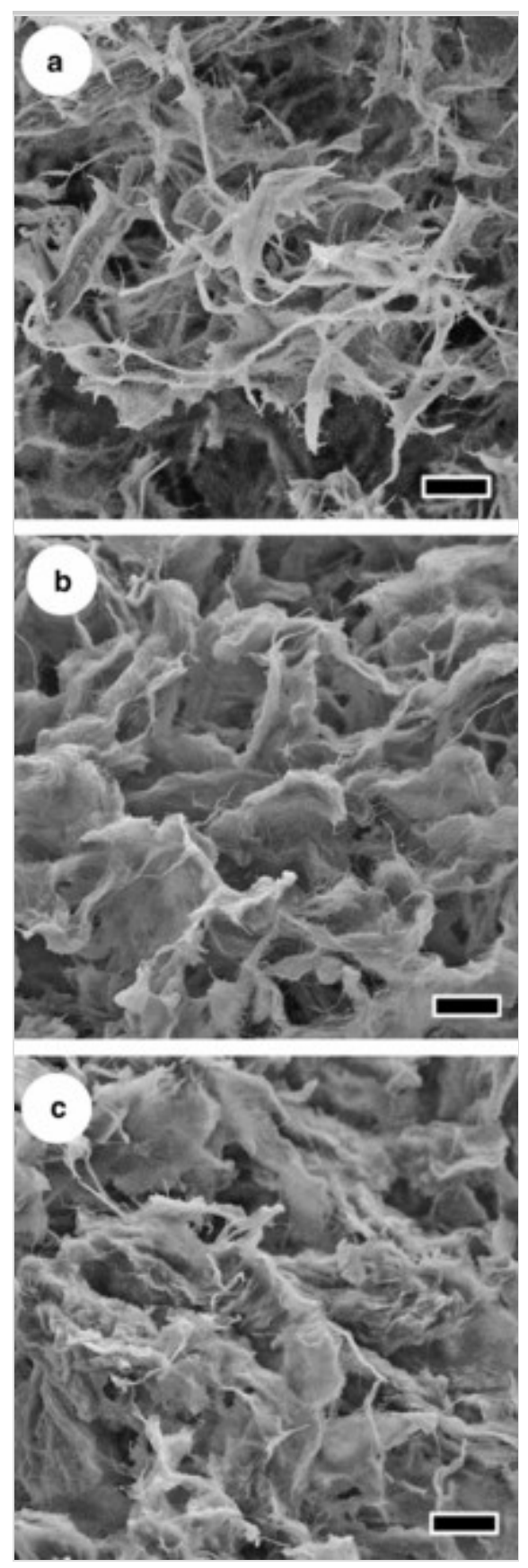

\section{Gas-phase grafting of the aerogels with sebacoyl chloride}

\section{Grafting the MFCs aerogels from bleached sulfite pine pulp}

Aerogels of MFCs from bleached sulfite pine pulp were grafted with sebacoyl chloride following the gas-phase process described in the experimental part and adapted from earlier work (Berlioz et al. 2009; Fumagalli et al. 2015). When achieved under a pressure as low as $0.5 \mathrm{mbar}$, at $100^{\circ} \mathrm{C}$ and for $12 \mathrm{~h}$, a complete 
surface grafting was achieved, and, as expected with the difunctional sebacoyl reagent, the modification was restricted only to the microfibrils surface (Fumagalli et al. 2015). Analysis of the samples was performed by FTIR spectroscopy (Fig. S1). In the corresponding spectra, next to $2900 \mathrm{~cm}^{-1}$, the grafting occurrence was identified by a modification in the bands attributed to the alkyl groups of the sebacoyl moiety, together with a new small band near $1750 \mathrm{~cm}^{-1}$ corresponding to the carbonyl ester groups.

The grafted samples were also analyzed by ${ }^{13} \mathrm{C}$ solid state NMR (Fig. 5). Two sets of resonances, not present in the un-grafted sample, were attributed to the grafted moiety: a triplet near $30 \mathrm{ppm}$ corresponding to the alkyl signal and a small singlet at $175 \mathrm{ppm}$ attributed to the carbon atom of the $\mathrm{C}=\mathrm{O}$. Unreacted sebacoyl was not detected in the spectra, since its identification resonance near $170 \mathrm{ppm}$ was not observed. As mentioned in previous reports (Berlioz et al. 2009; Fumagalli et al. 2013b), the absence of the resonance near $170 \mathrm{ppm}$ indicates (1) that the acetone soxhlet purification of the samples was effective, (2) that both ends of the sebacoyl molecules were engaged into an ester linkage with the microfibril surface.

\section{Fig. 5}

${ }^{13} \mathrm{C}$ solid state NMR spectra of aerogels of MFCs from bleached sulfite pine pulp, grafted with sebacoyl chloride. From top to bottom: grafted aerogels on freezedried suspensions in pure TBA; in $65 \mathrm{wt} \% \mathrm{TBA} /$ water; in $44 \mathrm{wt} \% \mathrm{TBA} /$ water; in $8 / 92 \mathrm{wt} \% \mathrm{TBA} /$ water; in pure water; aerogel prepared from pure TBA, but non grafted 


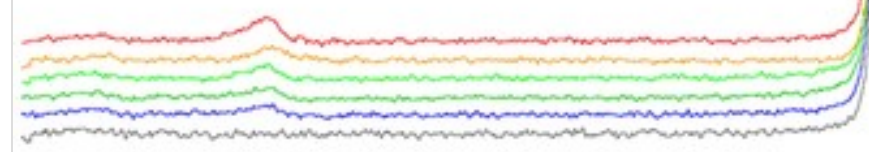

150

100

50

As shown in earlier reports (Berlioz et al. 2009; Fumagalli et al. 2013a, b, 2015), one can calculate the degree of substitution (DS) corresponding to each sample by spectral integration. In the present case, the $\mathrm{C}=\mathrm{O}$ singlet is rather small and difficult to integrate with precision (Fig. 5) and we rather used the integration from the alkyl carbons near $30 \mathrm{ppm}$. The integration results, presented in Table $\mathrm{S} 1$, indicate that for the samples from pine sulfite bleached pulp, the aerogels presented overall DSs ranging from 0.022 per anhydro glucose units (AGU) for samples prepared by freeze-drying from pure water, to 0.075 for those produced by freeze-drying from almost pure TBA. Besides these extreme values, one notices that there is a remarkable concordance between the specific surface area measurements of the samples before grafting, measured by BET, and the DS of the various grafted samples (Fig. 6). For these two sets of measurements, there is a local maximum for samples prepared from $25 \mathrm{wt} \% \mathrm{TBA} /$ water and a local minimum for those prepared from $45 \mathrm{wt} \% \mathrm{TBA} /$ water. In fact, this concordance between specific surface area and grafting confirms with a full set of values the earlier observations made on grafted MFC aerogels (Fumagalli et al. 2015).

\section{Fig. 6}

Grafted aerogels from microfibrillated bleached sulfite pine pulp: evolution of the specific surface area and DS of the grafted samples as a function of the TBA 
percentage in the freeze drying of the initial aerogels. Concordance of the DS values with those of the specific surface area measurements of the aerogels samples before grafting

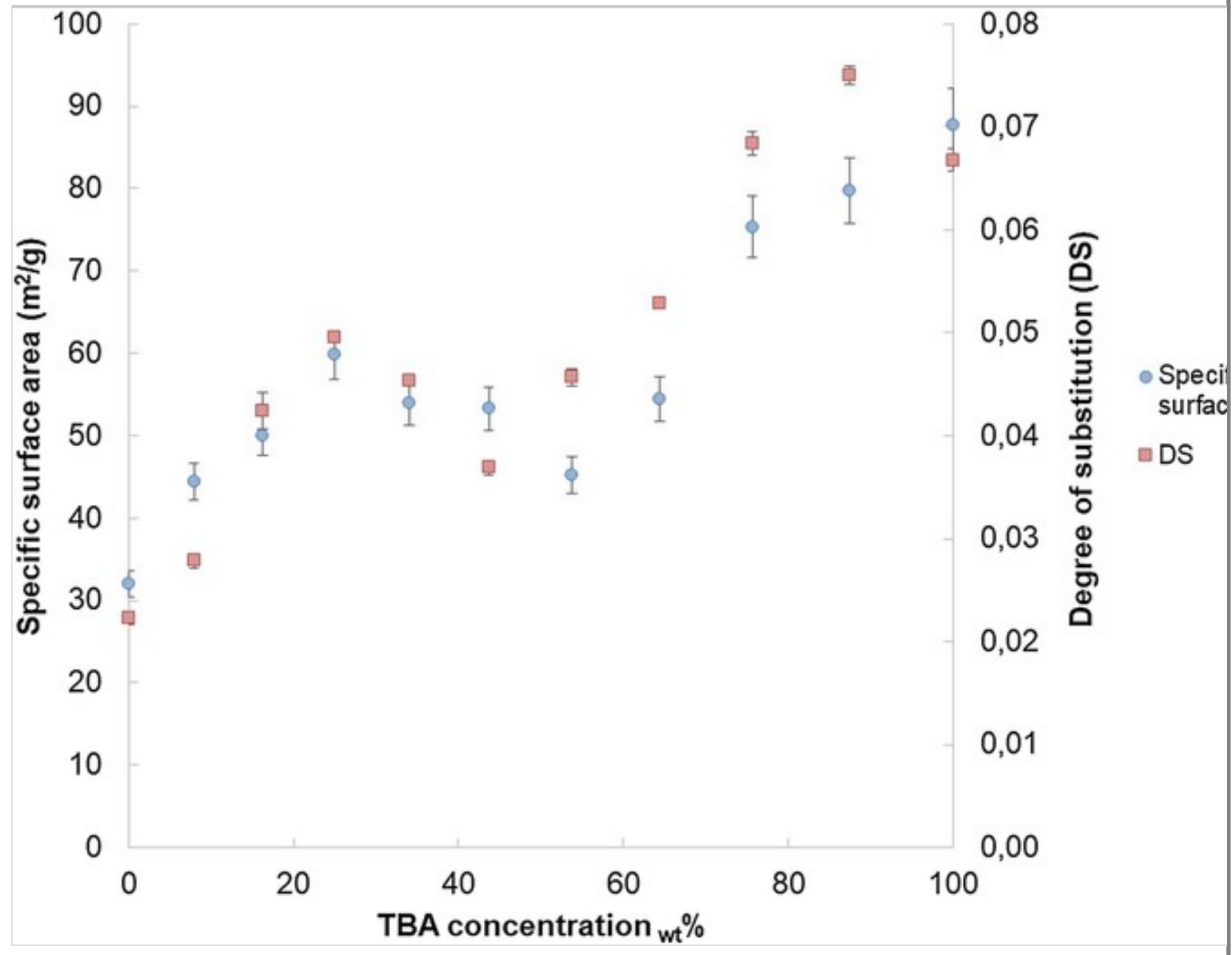

\section{Grafting the MFCs aerogels from other pulps}

The same grafting procedure was applied to MFC from bleached and unbleached kraft pulps. The relationship between the specific surface area measurement of the whole series of samples before grafting and the amount of grafting, deduced from ${ }^{13} \mathrm{C}$ NMR spectra (Fig. S2) is plotted, not only for the samples prepared from bleached sulfite pine pulp, but also for those from bleached and unbleached birch kraft pulps (Fig. 7). All the investigated samples followed a common trend and nicely fall close to a straight line within the experimental uncertainties, confirming the proportional relation between the grafting density and the specific surface area. Quite remarkably, the aerogel from unbleached birch kraft MFCs, 
freeze dried from pure TBA, which had shown the spectacular specific surface area of $280 \mathrm{~m}^{2} / \mathrm{gm}$, is also the one which shows the highest DS, reaching the value of 0.20 . This observation, together with those resulting from bleached birch kraft pulp and bleached sulfite pine pulp indicate that sebacoyl chloride is comparably active toward left-over hemicelluloses and lignin as with bare cellulose surfaces. It is interesting to note that despite such large variations in specific surface area measurement, morphological differences could not be observed by SEM imaging of the sections of the aerogels (Fig. S3). As aforementioned, at the resolution of the images the distinction between the morphology of the samples before and after grafting could not be clearly made, confirming the dominant role of the crystallization of the solvent during the freeze-drying step for the morphology at this intermediate scale.

\section{Fig. 7}

DS of grafted aerogels as a function of the specific surface area of the specimens before grafting. In green: aerogels from bleached pine sulfite (prepared from a series of TBA/water compositions, described in Table S1). In red: aerogels from bleached birch kraft pulp (from left to right: prepared from pure water; $44 \mathrm{wt} \%$ TBA/water; pure TBA. In brown: aerogels from unbleached birch kraft (from left to right: prepared from pure water; $44 \mathrm{wt} \% \mathrm{TBA} /$ water; pure TBA) 


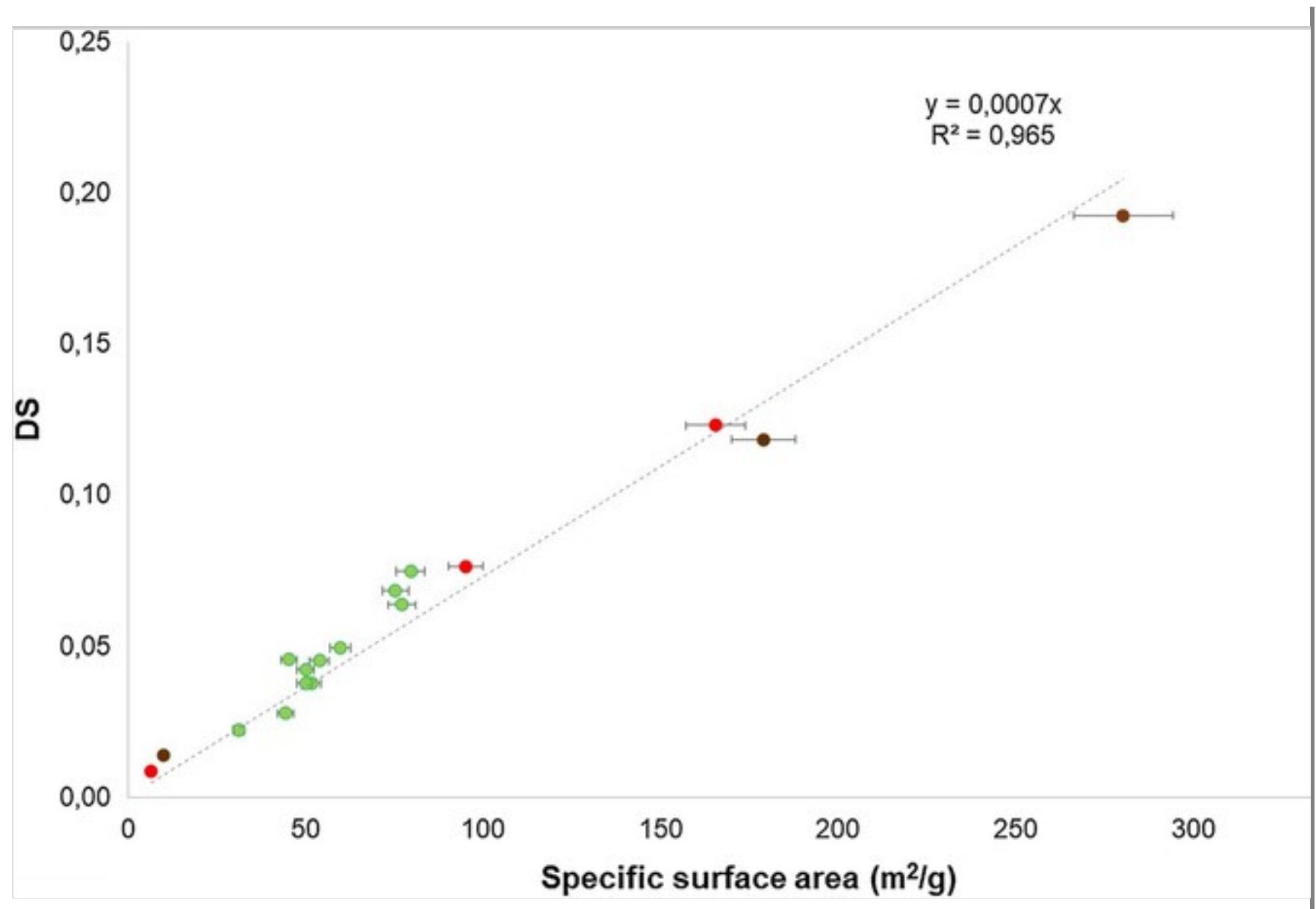

From these results, one can attempt to calculate the number of grafted molecules per surface area, assuming that (1) all the surface sites accessible to nitrogen are also accessible to sebacoyl chloride; (2) all the sebacoyl moieties are grafted from both ends. This latter hypothesis is largely supported by the nonobservation of free carboxylic moieties that have a contribution at a much lower chemical shift than the ester in the ${ }^{13} \mathrm{C}$ solid state NMR spectra (Fumagalli et al. $2013 \mathrm{a}, \mathrm{b}$ ). Based on geometrical consideration, the relation between the degree of substitution, the specific surface area and the number $n$ of grafted molecules per $\mathrm{nm}^{2}$ can be established in Eq. 1:

$$
n=\frac{D S \cdot N_{A}}{162 S S_{A} \cdot 10^{18}}
$$

where $n$ is the number of grafted molecules per $\mathrm{nm}^{2}, D S$ is the grafting density for an AGU unit, $N_{A}$ is the Avogadro number, 162 is the molecular weight of one $\mathrm{AGU}$ and $\mathrm{SS}_{\mathrm{A}}$ is the specific surface area of the aerogel in $\mathrm{m}^{2} / \mathrm{g}$.

Applying this equation to the various aerogels that were studied, one can give an 
average grafting density for each sample. This density presented in Fig. 8, indicates that for the samples from bleached sulfite pine pulp (green dots), between 2.35 and 3.8 (with an average of 3.08) grafted molecules per $\mathrm{nm}^{2}$ likely occur at the sample surface. For the aerogel samples originating from birch pulp, those having the lowest SSA (in water) present the highest grafting density, with values reaching 5 grafted molecules per $\mathrm{nm}^{2}$, but these points can be discarded as the measurements of very low specific surface area (i.e. $<5 \mathrm{~m}^{2} / \mathrm{g}$ ) is below the limit of the measurement accuracy. On the other hand, those showing the highest SSA (i.e. $>20 \mathrm{~m}^{2} / \mathrm{g}$ ), in pure TBA, reach values slightly lower than 3 grafted molecules per $\mathrm{nm}^{2}$, not too far from the average of the values for the samples prepared from bleached pine sulfite pulp. This concordance confirms again that both microfibrillar surfaces, those of pure cellulose and those with surface encrusted with non-cellulosic components, are comparably reactive toward our gas-phase surface derivatization process.

\section{Fig. 8}

Surface grafting density as a function of the specific surface area for grafted aerogels. In green: aerogels from bleached pine sulfite pulp MFCs (prepared with the TBA/water compositions described in Table S1). In red: aerogels from bleached birch kraft pulp MFCs (from left to right: prepared from pure water; 44 wt $\%$ TBA/water; pure TBA. In brown: aerogels from unbleached birch kraft pulp MFCs (prepared from left to right: pure water; $25 \mathrm{wt} \% \mathrm{TBA} /$ water; pure TBA) 


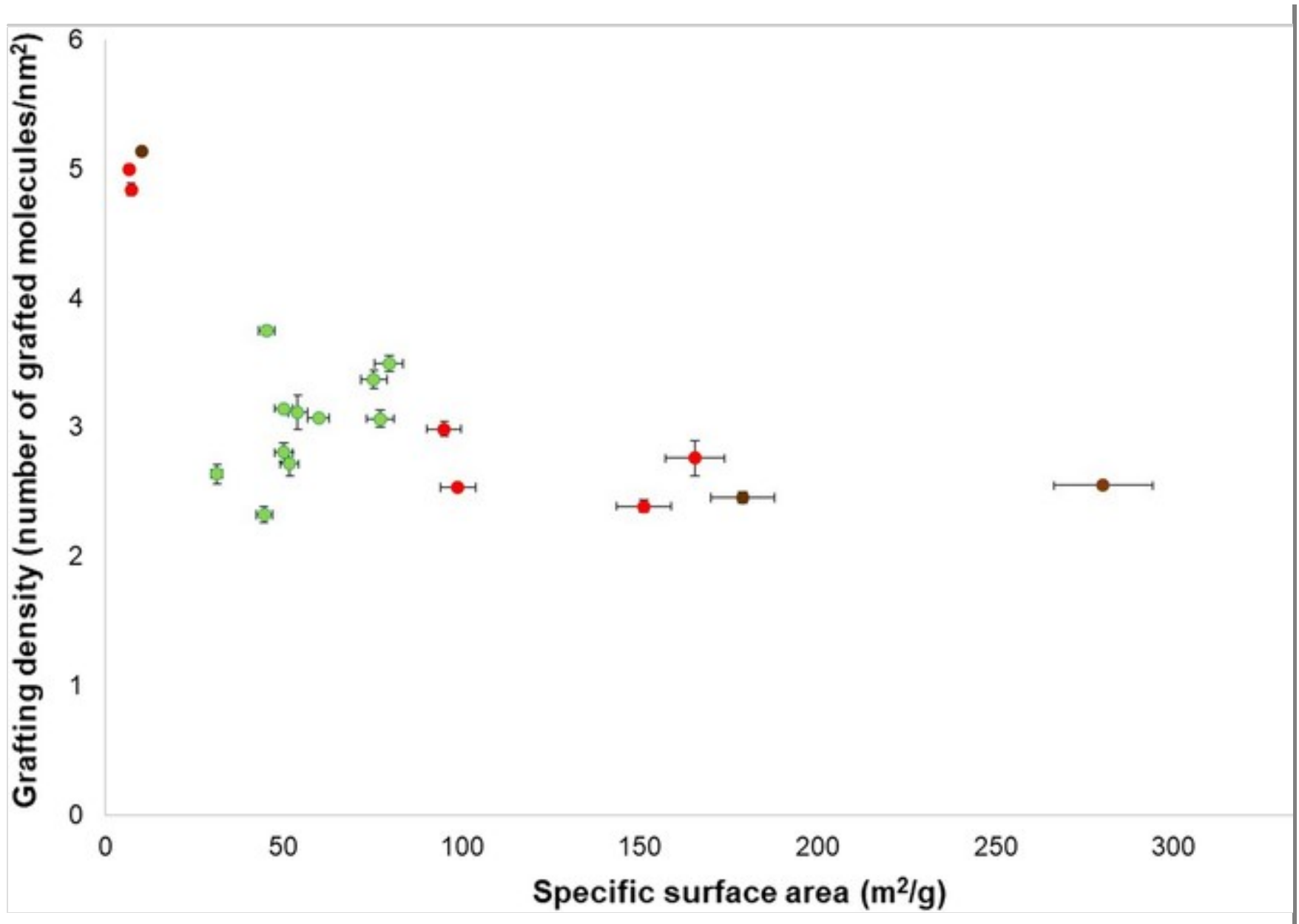

The average number of grafted molecules per $\mathrm{nm}^{2}$ can also be easily extracted from the $\rho$ slope of the linear fit of the data:

$$
\rho=\frac{\left(\mathrm{n}^{*} 162\right) * 10^{18}}{N_{A}}
$$

From a $\rho$ of 0.00073 , a grafting density of 2.7 molecules per $\mathrm{nm}^{2}$ can be derived, very close to the aforementioned average number of grafted molecules. At this stage, it would most probably be difficult to make differences between the different substrates.

From a topochemical point of view, hydroxyl densities of $5 \mathrm{OH}$ per $\mathrm{nm}^{2}$ can be calculated from the crystalline lattice calculated at the surface of a model crystalline wood cellulose microfibril of $3.5 \mathrm{~nm}$ diameter with a square section made by Fumagalli et al. (2013a, b). That roughly means that almost all hydroxyl sites have reacted and have been transformed in an ester bond so that the reaction 
can be considered as quantitative.

\section{Modeling}

In order to investigate the possible arrangement of the sebacoyl moieties on the surface of the cellulose microfibrils, we performed a molecular modeling study of the surface grafting of three sebacoyl moieties per $\mathrm{nm}^{2}$ on the hydrophilic (110) and (1-10) surfaces of crystalline cellulose I $\beta$, in agreement with the experimental data. These two surfaces are believed to correspond to the skin of neat cellulose microfibrils, in the absence of surface hemicellulose and/or lignin. For both models, shown in Fig. 8 for the (110) surface and Figure S4 for the (1-10) counterpart, this coverage is dense as most of the surface cellulose OHs are engaged in ester bonds, leading to a strongly alkylated surface. Nevertheless, even if the surface is rather crowded, there is no short contact as the sebacoyl moieties keep an inherent conformational mobility, which allows them to search and react with the available surface $\mathrm{OH}$ groups.

Grafting densities of up to five sebacoyl moieties were calculated for the cellulose samples exhibiting the lowest specific surface areas. In our modelling attempt, it was impossible to place so many sebacoyl entities at the (1-10) or (110) surfaces of crystalline cellulose without strong steric clashes if both ends of sebacoyl are required to be esterified. This confirms that this average number of around 3 grafted molecules per $\mathrm{nm}^{2}$ is not only viable in terms of crowding at the cellulose surface, but also a kind of maximum coverage of a model cellulosic surface, bringing a strong argument for the efficiency of the grafting process.

\section{Fig. 9}

Atomistic model of the hydrophobic layer of 3 sebacolyl chloride per $\mathrm{nm}^{2}$, grafted at the surface of a (110) plane of crystalline cellulose. Atoms color code: hydrogen: white; carbon: grey; oxygen from the $\mathrm{C}=\mathrm{O}$ : red; cellulose, blue. a top view; b side view showing the grafted sebacoyl sheet atop two molecular layers of a cellulose crystal 

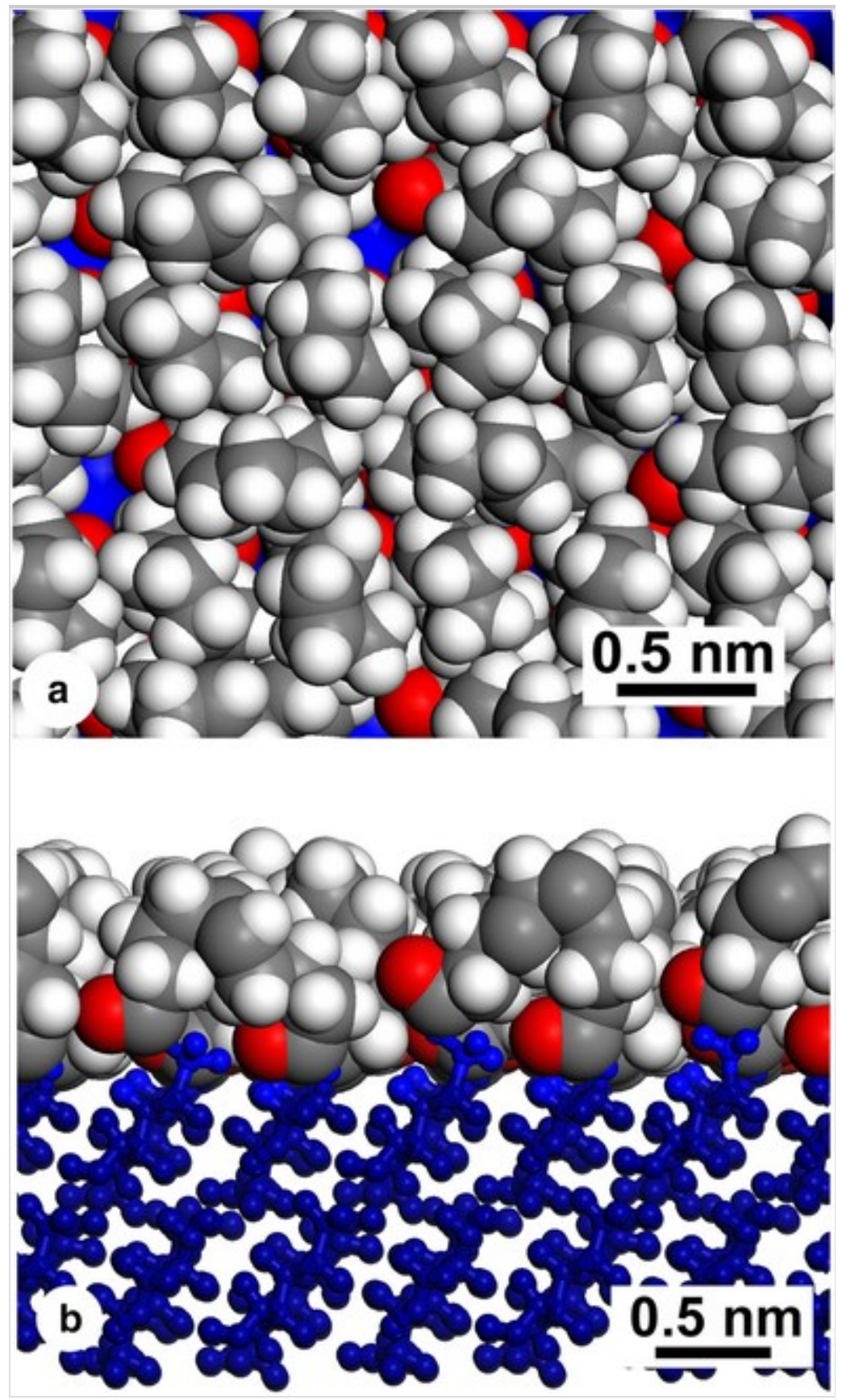

\section{Hydrophobicity of the grafted samples}

The hydrophobicity of the grafted samples was probed by contact angle measurements in the case of aerogels from bleached pine sulfite MFCs. This analysis was not only applied to the samples that were fully grafted, but also to some partially grafted aerogels by using milder conditions $(250 \mathrm{mbar}, 3 \mathrm{~h}$ instead of $0.5 \mathrm{mbar}, 12 \mathrm{~h}$ ). Such samples presented DSs ranging from 0.007 to 0.038 (Table S1) for samples prepared from freeze-dried MFCs from bleached sulfite pine pulp in various water/TBA compositions. On contact angle characterization, 
some samples grafted with lowest DS presented a surface grafting heterogeneity, with some hydrophilic areas where the water droplet dropped into the sample, and some hydrophobic surfaces. Interestingly, all the hydrophobic areas showed contact angles greater than $120^{\circ}$ (Fig. 9a and b) and it was not possible to note a substantial difference in the surface hydrophobicity of the surfaces, even with the sample with a DS as low as 0.006 . This latter observation is well correlated with the idea of a dense monolayer of grafted sebacoyl moieties, which act as a protecting skin against water. As the reaction presumably limited by the diffusion of the reactant, the presence of hydrophilic patches in the less grafted samples is most probably due to the impossibility for the sebacoyl chloride to reach every part of the exposed surface of the aerogels in the less harsh conditions. This last observation also confirms the full coverage of the hydrophilic surface by the hydrophobic sebacoyl moieties (Fig. 10).

\section{AQ2}

\section{Fig. 10}

Contact angle measurements on grafted aerogels from bleached sulfite pine pulp. a Droplet of water deposited at the surface of aerogel of MFCs from bleached sulfite pulp freeze-dried from water. Left: sample of DS 0.006; right sample of DS 0.023. b Contact angles on grafted aerogel prepared from various TBA/water compositions. In pale red: low grafting density and in dark red; high grafting density. A Grafted aerogel produced from freeze-drying MFCs in pure water; $\mathbf{B}$ in $8 \mathrm{wt} \% \mathrm{TBA} /$ water; $\mathbf{C}$ in $44 \mathrm{wt} \% \mathrm{TBA} /$ water; $\mathbf{D}$ in $66 \mathrm{wt} \% \mathrm{TBA} /$ water; $\mathrm{E}$ : in pure TBA 


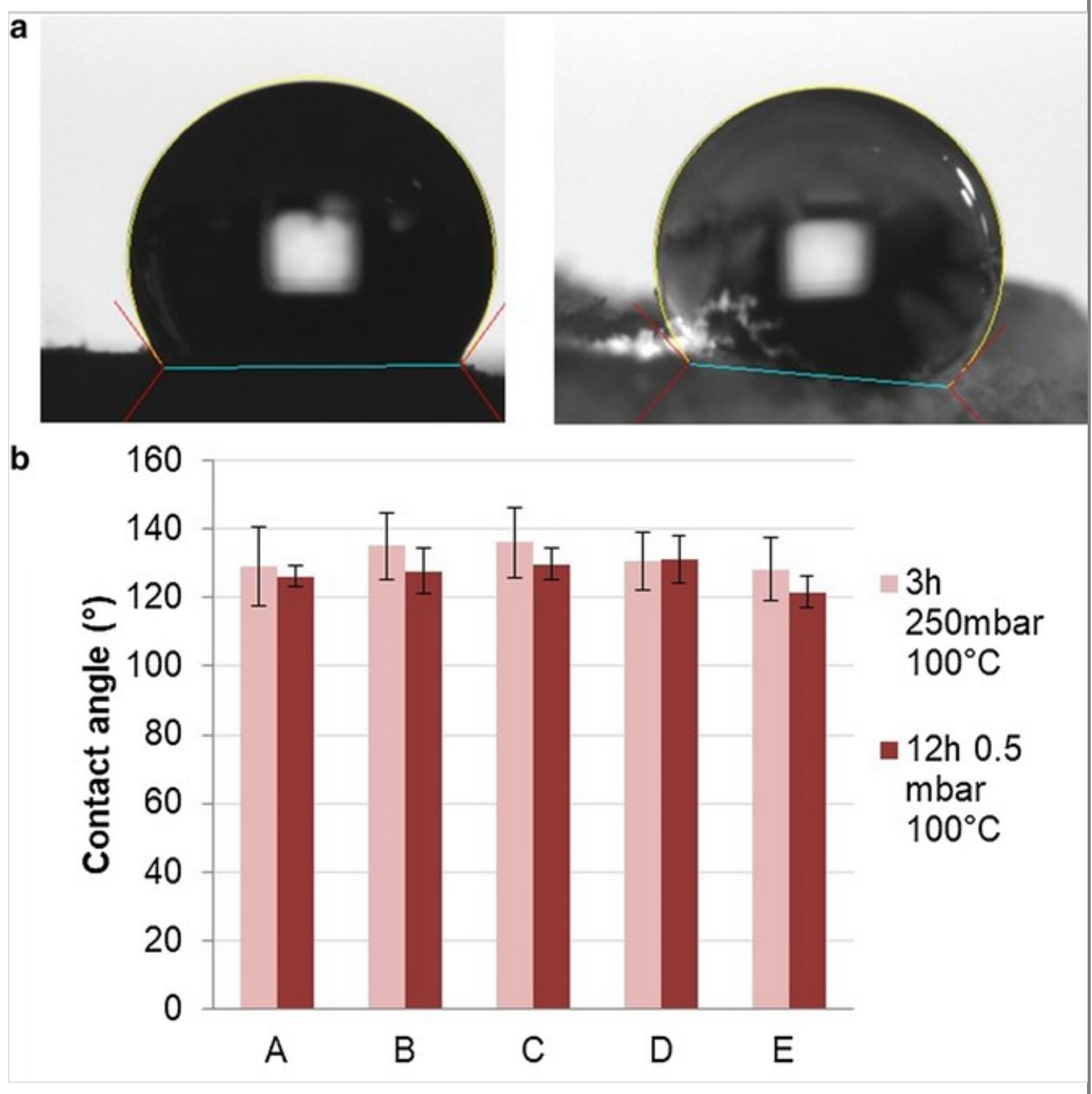

\section{Conclusions}

In this study, we have shown that we were able to produce aerogels of tunable specific surface area by freeze-drying some mixtures of aqueous suspensions of microfibrillated cellulose exchanged with variable proportions of TBA. An additional tunability was also obtained by choosing cellulose samples of various purities: specimens with residual lignin freeze-dried from pure TBA leading to aerogels presented the highest specific surface area. 
When the aerogels were surface-esterified by sebacoyl chloride in a gas-phase process, a linear correlation was found between the grafting density and the specific surface area of the specimens, even in the case where amounts of hemicelluloses and lignin were still present at the microfibril surface. This specificity indicates that the reactivity of the hydroxyl moieties of cellulose and that of eventual left-over surface encrustants is the same toward our gas-phase esterification scheme. All the prepared grafted aerogels were strongly hydrophobic, showing contact angles of $120^{\circ}$ and higher even at very low surface grafting, despite some heterogeneities. By modeling, it was shown that a full surface coverage of the cellulose microfibrils was achieved with three molecules of sebacoyl moieties per $\mathrm{nm}^{2}$, esterified at both ends with the surface $\mathrm{OH}$ of cellulose, in close agreement with the experimental values deduced from the observed DSs of the fully grafted samples.

Our hydrophobized aerogels are obtained with a very robust and simple chemistry, and could find applications as oil spillage absorbents, which are in high demand and subject of intense research and development. Other possibilities, already in development in our laboratory (Fumagalli et al. 2018) are in their use as fillers in the melt processing of commodity hydrophobic polymers.

\section{Publisher's Note}

Springer Nature remains neutral with regard to jurisdictional claims in published maps and institutional affiliations.

\section{Acknowledgments}

We acknowledge the financial support from Institut Carnot PolyNat (ANR No. 16-CARN-025-01) and the Glyco@Alps program (Investissements d'Avenir Grant No. ANR-15-IDEX-02). We also thank Ms. A Guillemain from FCBA for the sugar analysis, Ms. C. Lancelon-Pin from CERMAV for the SEM images and Dr. H. Chanzy for fruitful discussions during the writing of this manuscript. The NMR spectra were recorded with a spectrometer from the Institut de Chimie Moléculaire de Grenoble (ICMG, FR 2607).

Compliance with ethical standards

Conflict of interest The authors declare that they have no conflict of interest. 


\section{Electronic supplementary material}

Below is the link to the electronic supplementary material.

Supplementary material 1 (PDF $1445 \mathrm{~kb}$ )

\section{References}

Aulin C, Netrval J, Wågberg L, Lindström T (2010) Aerogels from microfibrillated cellulose with tunable oleophobicity. Soft Matter 6:3298-3305

Arola S, Mahlo J-M, Laaksonen P, Lille M, Linder MB (2013) The role of hemicellulose in nanofibrillated cellulose networks. Soft Matter 9:1319-1326

Berlioz S, Molina-Boisseau S, Nishiyama Y, Heux L (2009) Gas-phase surface esterification of cellulose microfibrils and whiskers. Biomacromol 10:2144-2151. https://doi.org/10.1021/bm900319k

Brunauer S, Emmett PH, Teller E (1938) Adsorption of gases in multimolecular layers. J Am Chem Soc 60:309-319

Borisova A, De Bruyn M, Budarin VL, Shuttleworth PS, Dosdon JR, Sehgatto ML, Clark JH (2015) A sustainable freeze-drying route to porous polysaccharides with tailored hierarchical meso- and macroporosity. Macromol Rapid Com 36:774-779

Chen W, Yu H, Li Q, Liu Y, Li J (2011) Ultralight and highly flexible aerogels with long cellulose I nanofibers. Soft Matter 7:10360-10368

Chen W, Li Q, Wang Y, Yi X, Zeng J, Yu H, Liu Y, Li J (2014) Comparative study of aerogels obtained from differently prepared nanocellulose fibers. Chem Sus Chem 7:154-161

De France KJ, Hoare T, Cranston ED (2017) Review of hydrogels and aerogels containing nanocellulose. Chem Mater 29:4609-4631. https://doi.org 
Ding B, Cai J, Huang J, Zhang L, Chen Y, Shi Y, Du Y, Kuga S (2012) Facile preparation of robust and biocompatible chitin aerogels. J Mater Chem 22:5801-5809

Druel L, Bardl R, Vorwerg W, Budtova T (2017) Starch aerogel: a member of the family of thermal superinsulating materials. Biomacromol 19:4232-4239

Evans DJ, Holian BL (1985) The Nose-Hoover thermostat. J Chem Phys 83:4069-4074

Fumagalli M, Ouhab D, Molina-Boisseau S, Heux L (2013) Versatile gasphase reactions for surface to bulk esterification of cellulose microfibrils aerogels. Biomacromol 14:3246-3255. https://doi.org/10.1021/bm400864z

Fumagalli M, Sanchez F, Molina-Boisseau S, Heux L (2013) Gas-phase esterification of cellulose nanocrystal aerogels for colloidal dispersion in apolar solvents. Soft Matter 9:113096-111317. https://doi.org/10.1039 /c3sm52062e

Fumagalli M, Sanchez F, Molina-Boisseau S, Heux L (2015) Surfacerestricted modification of nanocellulose aerogels in gas-phase esterification by di-functional fatty acid reagents. Cellulose 22:1451-1457. https://doi.org /10.1007/s10570-015-0585-3

Fumagalli M (2013) Elaboration et caractérisation de nanocomposites à base de renforts biosourcés. Doctoral Dissertation, University of Grenoble

Fumagalli M, Berriot J, De Gaudemaris B, Veyland A, Putaux J-L, MolinaBoisseau S, Heux L (2018) Rubber materials from elastomer and nanocellulose powders: filler dispersion and mechanical reinforcement. Soft Matter 14:2638-2648

Garcia-Gonzales CA, Alnaief M, Smirnova I (2011) Polysaccharide-based aerogels. Promising biodegradable carrier for drugs delivery system.

Carbohydr Polym 86:1425-1438 
Gesser HD, Goswami PC (1989) Aerogels and related porous materials. Chem Rev 89:765-788

Gun'ko VM, Savina I, Mikhalovsky V (2013) Cryogels: morphological, structural and adsorption characterization. Adv Coll Interf Sci 187-188:1-46

Gutierrez MC, Ferrer ML, del Monte F (2008) Ice-templating materials: sophisticated structures exhibiting enhanced functionalities obtained after unidirectional freezing and ice-segregation-induced self-assembly. Chem Mater 20:634-648

Groult S, Budtova T (2018) Thermal conductivity/structure correlations in thermal super-insulating pectin aerogels. Carbohydr Polym 196:73-81

Hüsing N, Schubert U (1998) Aerogels-airy materials: chemistry, structure, and properties. Angew Chem Int Edit 37:22-45

Isogai A (2013) Wood nanocellulose: fundamentals and applications as new biobased nanomaterials. J Wood Sci 59:449-459

Iwamoto S, Kai W, Isogai A, Iwata T (2009) Elastic modulus of single cellulose microfibrils from tunicate measured from atomic force microscopy. Biomacromol 10:2571-2576

Kasraian K, DeLuca PP (1995a) Thermal analysis of the tertiary butyl alcohol-water system and its implication on freeze-drying. Pharm Res $12: 484-490$

Kasarian K, DeLuca PP (1995b) The effect-of tertiary butyl alcohol on the resistance of the dry product layer during primary drying. Pharm Res $12: 491-495$

Kistler SS (1931) Coherent expanded aerogels and jellies. Nature 127:741

Klemm D, Heublein B, Fink H-P, Bohn A (2005) Cellulose: Fascinating biopolymer and sustainable raw material. Angew Chem Int Edit 44:3358-3393. https://doi.org/10.1002/anie.200460587 
Lazzari L, Zampieri VB, Zanini M, Zattera AJ, Baldasso C (2017) Sorption capacity of hydrophobic cellulose cryogels silanized by different methods. Cellulose 24:3421-3431

Liebner F, Haimer E, Wendland M, Neouze M-A, Sclufter K, Miethe P, Heinze T, Potthast A, Roseneau T (2010) Aerogels from unaltered bacterial cellulose: application of scCO2 drying for the preparation of shaped, ultralightweight cellulosic aerogels. Macromol Biosci 10:349-352

Lindström T, Ankerfors M, Henrirksson G (2007) Method for the manufacturing of microfibrillated cellulose. WO 2007/091942

Mazeau K (2011) On the external morphology of native cellulose microfibrils. Carbohydr Polym 84:524-532

Meyer V, Petit-Conil M, Lecourt M, Soranzo A (2017) Method for producing microfibril cellulose. WO 2017/216438

Moon RJ, Martini A, Nairn J et al (2011) Cellulose nanomaterials review: structure, properties and nanocomposites. Chem Soc Rev 40:3941-3994. https://doi.org/10.1039/c0cs00108b

Nishiyama Y, Langan P, Chanzy H (2002) Crystal structure and hydrogenbonding system in cellulose I $\beta$ from synchrotron $X$-ray and neutron fiber diffraction. J Am Chem Soc 124:9074-9062

Nishiyama Y (2009) Structure and properties of the cellulose microfibril. J Wood Sci 55:241-249

Ott JB, Goates JR, Waite BA (1979) (Solid + liquid) phase equilibria and solid-hydrate formation in water + methyl, + ethyl, + isopropyl, and + tertiary butyl alcohols. J Chem Thermodyn 11:739-746

Pääkkö M, Ankerfors M, Kosonen H et al (2007) Enzymatic hydrolysis combined with mechanical shearing and high-pressure homogenization for nanoscale cellulose fibrils and strong gels. Biomacromol 8:1934-1941. https://doi.org/10.1021/bm061215p 
Pääkkö M, Vapaavuori J, Silvennoinen R, Kosonen H, Ankerfors M, Lindström T, Berglund L, Ikkala O (2008) Long and entangled native cellulose I nanofibers allow flexible aerogels and hierarchically porous templates for functionalities. Soft Matter 4:249-252. https://doi.org/10.1039 /b810371b

Pierre AC, Pajonk GM (2002) Chemistry of aerogels and their applications. Chem Rev 102:4243-4265

Pons A, Casas L, Estop E, Molins E, Harris KDM, Xu M (2012) A new route to aerogels: monolithic silica cryogels. J Non-Cryst Solids 358:461-469

Rappe AK, Goddard WA, III (1991) Charge equilibration for molecular dynamics simulation. J Phys Chem 95:3358-3363

Rappe AK, Casewit CJ, Colwell WA, Goddard WA, Skiff III, W. M (1992) UFF, a full periodic table force field for molecular mechanics and molecular dynamics simulation. J Am Chem Soc 114:10024-10035

Reichardt C, Welton T (2010) Solvents and Solvent Effects in Organic Chemistry. Wiley, Weinheim

Ren L, Cui S, Cao F, Guo Q (2014) An easy way to prepare monolithic inorganic oxide aerogels. Angew Chem Int Edit 53:10147-10148

Rudaz C, Courson R, Bonnet L, Cals-Etienne S, Sallée H, Budtova T (2014) Aeropectin : fully biomass-based mechanically strong and thermal superinsulating aerogel. Biomacromol 15:2188-2195

Saito T, Kuramae R, Wohlert J, Berglund LA, Isogai A (2013) An ultrastrong nanofibrillar biomaterial: the strength of single nanofibrils revealed via sonication-induced fragmentation. Biomacromol 14:248-253

Schaefer JR, Rasmussen DH, Partch R (2013) Freeze-drying of aluminum nanoflakes from cyclohexane suspensions. Dry Technol 31:856-863

Sehaqui H, Salajková M, Zhou Q, Berglund LA (2010) Mechanical 
performance tailoring of tough ultra-high porosityfoams prepared from cellulose I nanofiber suspensions. Soft Matter 6:1824-1832. https://doi.org /10.1039/B927505C

Sehaqui H, Zhou Q, Berglund LA (2011) High-porosity aerogels of high specific surface area prepared from nanofibrillated cellulose (NFC). Compos Sci Technol 71:1593-1599. https://doi.org/10.1016/j.compscitech.2011.07.003

Sugiyama J, Vuong R, Chanzy H (1991) Electron diffraction study on the two crystalline phases occurring in native cellulose from an algal cell wall. Macromolecules 24:2461-2466

Tamon H, Ishizaka H, Yamamoto T, Suzuki T (1999) Preparation of mesoporous carbon by freeze-drying. Carbon 37:2049-2055

Tamon H, Ishizaka H, Yamamoto T, Suzuki T (2000) Influence of freezedrying conditions on the mesoporosity of organic gels as carbon precursors. Carbon 38:1099-1105

Vareda JP, Lamy-Mendes A, Duraes L (2018) A reconsideration on the definition of the term aerogel based on current drying trends. Micropor Mesopor Mat 258:211-216

Verlet L (1967) Computer "experiments" on classical fluids. I. Thermodynamical properties of Lennard-Jones molecules. Phys Rev 159:98-103

Wang S, Peng X, Zhong L, Tan J, Jing S, Cao X, Chen W, Liu C, Sun R (2015) An ultralight, elastic, cost-effective, and highly recyclable super absorbent from microfibrillated cellulose fibers for oil spillage cleanup. $\mathrm{J}$ Mater Chem A 3:8772-8781

Wang X, Zhang Y, Jiang H, Song Y, Zhou Z, Zhao H (2017) Tert-butyl alcohol used to fabricate nano-cellulose aerogels via freeze-drying technology. Mater Res Express 4:065006

Zhou S, Liu P, Wang M, Zhao H, Yang, J, Xu F (2016) Sustainable, reusable 
and superhydrophobic aerogels from microfibrillated cellulose for highly effective oil/water separation. ACS Sustain Chem Eng 4:6409-5416

Ziegler C, Wolf A, Liu W, Herrmann A-K, Gapponik N, Eychmüller A (2017) Modern inorganic aerogels. Anger Chem Inter Ed 56:13200-13221 